\title{
A Case of Rabies after Squirrel Bite
}

\author{
P. Leela Kumari • K. Raja Mohanan • \\ Lalitha Kailas • Kurien P. Chacko
}

Received: 14 November 2011 / Accepted: 4 February 2013 /Published online: 23 February 2013

(C) Dr. K C Chaudhuri Foundation 2013

To the Editor: A 7-y-old boy presented with fever, cough, restlessness, difficulty in taking oral feeds and aggressive behavior on giving oral fluids of $2 \mathrm{~d}$ duration. He was apparently normal before the onset of present symptoms. There was a past history of squirrel bite in the right leg 2 mo back and he was treated in a local hospital with injection Tetanus toxoid and wound management. No antirabies vaccine was given. There was no history of any other animal bite in the past.

On examination the child was febrile, anxious and agitated. Aerophobia and hydrophobia were present. Pulse rate was $100 / \mathrm{min}$ regular, Respiratory rate $28 / \mathrm{min}$, blood pressure 100/70 mm of $\mathrm{Hg}$. Examination of central nervous system revealed no signs of meningeal irritation or no focal neurologic deficits. Fundus examination was normal. Other systems were normal.

Child was treated in ICU with supportive measures. His general condition was deteriorating and died due to cardio respiratory arrest $4 \mathrm{~h}$ after admission. Corneal impression smear was positive for Rabies (Fluorescent antibody test).

Rabies is highly endemic in India and is a major public health problem. The animal reservoirs mainly responsible for human rabies are dogs $(96.3 \%)$. Cats accounts for $1.7 \%$ of rabies death. Other animal reservoirs are foxes, bats, jackals, horse, sheep, raccoons, skunks, cattle, pig, mongoose etc [1].
Small rodents are rarely infected, but there are reported cases especially in woodchucks $[2,3]$. Woodchucks accounted for $86 \%$ of 368 cases of rabies among rodents reported to CDC [3].

Diagnosis is mainly clinical. Laboratory tests include detection of viral antigens in the saliva or CSF (PCR) and corneal smear immunofluorescent examination [4].

Our case presented with typical features of rabies and definite preceding history of squirrel bite and it was confirmed by corneal impression smear examination. Hence it may be recommended that any rodent bite like squirrel bite should be taken seriously and proper post exposure antirabies prophylaxis should be advised.

\section{References}

1. APCRI. Burden of rabies in India. In: Sudarshan MK ed. Assessing Burden of Rabies in India: WHO sponsored National Multicentric Survey Bangalore: Association for Prevention and Control of Rabies in India; 2004. pp.44.

2. Rabies Fact sheet N 99. World Health Organization September 2011.

3. http://www.cdc.gov/rabies/pets/index.html.

4. Menezes R. Rabies in India. CMAJ. 2008;178:564-6.

P. L. Kumari $(\bowtie) \cdot$ K. R. Mohanan $\cdot$ L. Kailas

Department of Pediatrics, SAT Hospital, Medical College,

Trivandrum, India

e-mail: leela_suresh2005@yahoo.co.in

K. P. Chacko

Department of Pediatrics, ESI Corporation Hospital, Ezhukone, Kerala, India 